[1] M. Ceretti, O. Wahyudi, A. Cousson, A. Villesuzanne, M. Meven, B. Pedersen, J. M. Bassat and W. Paulus, J. Mater Chem. A, 2015, 3 (42), 21140-21148.

[2] O. Wahyudi, M. Ceretti, I. Weill, A. Cousson, F. Weill, M. Meven, M. Guerre, A. Villesuzanne, J.-M. Bassat and W. Paulus, CrystEngComm, 2015 17, 6278-6285.

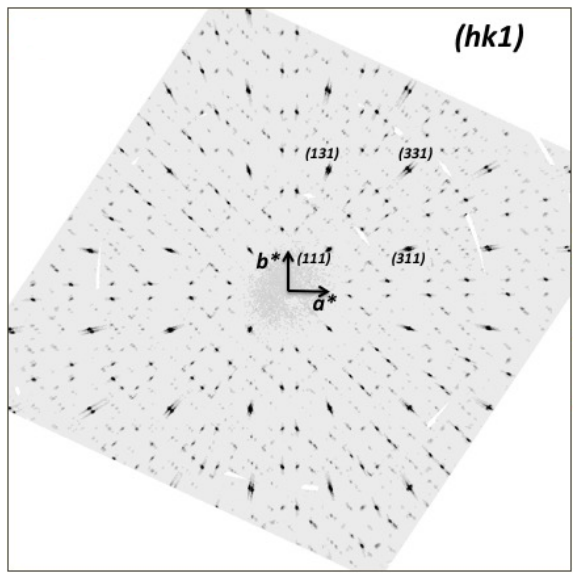

Figure 1. (hk1) reciprocal plane of $\mathrm{Pr}_{2} \mathrm{NiO}_{425}$ containing incommensurate superstructure reflections ${ }^{2}$ along with main reflections @RT reconstructed from X-ray single crystal diffraction data obtained on a STOE STADIVARI diffractometer (Mo Ka $\mu$-focus) equipped with a $2 \mathrm{D}$ Pilatus detector .

Keywords: Hole doped, Incommensurate modulation, Oxygen/charge ordering

\section{MS26-P2 The mystery of the AuIn 1:1} phase

\author{
Laura C. Folkers ${ }^{1}$, Sven Lidin ${ }^{1}$
}

1. Centre for Analysis and Synthesis, Lund University, Naturvetarvägen 14, 22362 Lund, Sweden

\section{email: laura.folkers@chem.lu.se}

Recently, the Gold Indium system has regained interest due to its importance for applications in soldering and nanowire growth. For these applications knowledge of the occurring components in the phase diagram is important. Earlier studies of this alloy were able to uncover most currently known compounds along with their crystal structures. Only the structure of the seemingly most straight-forward one, AuIn 1:1, has not been elucidated. Its lattice parameters are known from earlier experiments [1], but growth of single crystals has proved difficult.

The powder diffraction pattern contains unindexed peaks that cannot be explained by any known Au-In binary or by any known oxide or nitride. The problem is exacerbated by the tendency of the compound to amorphisize on grinding. Subsequent annealing at low temperature $\left(400^{\circ} \mathrm{C}\right)$ however restores full crystallinity.

Differential thermal analysis (DTA conf. Fig. 1) reveals further surprises. On heating, a small endothermic peak appears at $440^{\circ} \mathrm{C}$ while a second endotherm at $515^{\circ} \mathrm{C}$ corresponds well with the reported melting point of AuIn $\left(\mathrm{T}_{\mathrm{M}}=510^{\circ} \mathrm{C}[2]\right)$. On cooling only one exothermic peak can be observed, which, in position, corresponds to the low temperature exotherm at $440^{\circ} \mathrm{C}$, but in size it corresponds to the high temperature endotherm at $515^{\circ} \mathrm{C}$.

An electron diffraction study reveals weak satellites in AuIn, indicating that the structure may be incommensurately modulated [3].

In this study we will discuss structure models for AuIn and possible explanations for the thermal behaviour.

[1] K. Schubert, U. Rösler, M. Kluge, K. Anderko, L. Härle, Naturwissenschaften, 40, (1953), pp.437

[2] I. Ansara, J.-Ph. Nabot, CALPHAD, 16, (1992), pp. 13-18

[3] Wilder Carillo-Cabrera, unpublished work, (2014) 


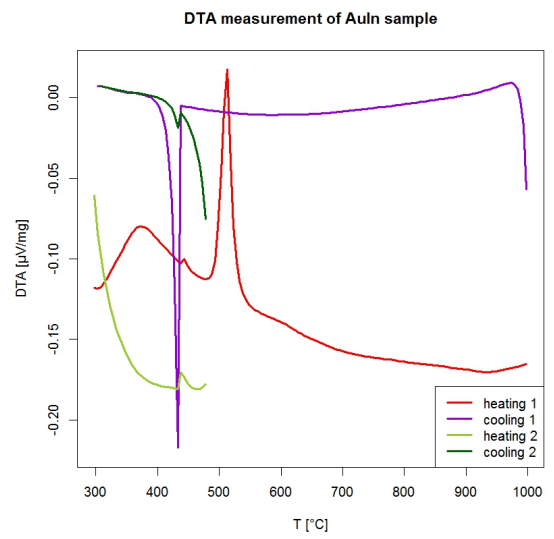

Figure 1. DTA curve showing a first melt at $\mathrm{T}=440^{\circ} \mathrm{C}$, a second one at $\mathrm{T}=515^{\circ} \mathrm{C}$ and solidification at $\mathrm{T}=436^{\circ} \mathrm{C}$.

Keywords: Intermetallics, modulation, powder diffraction

\author{
MS26-P3 $\mathrm{ErCu}_{0.5} \mathrm{Ga}_{3.5}-\mathrm{A}$ \\ $(3+1) \mathrm{D}$-incommensurately modulated \\ variant of the $\mathrm{BaAl}_{4}$ type \\ Margarida S. Henriques ${ }^{1}$, Yuriy Verbovytskyy ${ }^{2}$, Václav Petř́čček ${ }^{1}$, \\ Michal Dušek ${ }^{1}$, Vasyl Kinzhybalo ${ }^{3}$, António P. Gonçalves ${ }^{4}$ \\ 1. Institute of Physics, Academy of Sciences of the Czech \\ Republic, Na Slovance 2, 18221 Prague, Czech Republic \\ 2. Department No. 27, Karpenko Physico-Mechanical Institute of \\ the NAS of Ukraine, Naukova str. 5, 79-060 Lviv, Ukraine \\ 3. Institute of Low Temperature and Structure Research, Polish \\ Academy of Sciences, Okolna str. 2, PO Box 1410, 50-950 \\ Wroclaw, Poland \\ 4. CCTN, Instituto Superior Técnico, Universidade de Lisboa, \\ Estrada Nacional 10, 2695-066 Bobadela LRS, Portugal
}

email: henriques@fzu.cz

Ternary intermetallic systems $\mathrm{R}-\mathrm{Cu}-\mathrm{Ga}$ were widely studied for all the rare earth metals and uranium [1,2]. The gallium rich intermediate phases $R \mathrm{Cu} \mathrm{Ga}_{4}$ were reported to crystallize as tetragonal or orthorhombically distorted derivatives of the $\mathrm{BaAl}_{4}$-type structure [3]. Moreover, some of these phases tend to form modulated structures due to disorder that might occur in the $\mathrm{R}$ and/or $\mathrm{Cu} / \mathrm{Ge}$ crystal sublattices [4].

Single crystals of the ternary compound $\mathrm{ErCu}_{05} \mathrm{Ga}_{35}$ were grown by the self-flux method. The structure of $\mathrm{ErCu}_{0.5} \mathrm{Ga}_{3.5}$ was determined by single-crystal X-ray diffraction recorded at 120 and $300 \mathrm{~K}$. The compound crystallizes in an incommensurately modulated $(3+1) \mathrm{D}$ structure, being related to the tetragonal $\mathrm{BaAl}_{4}$-type. The structure was refined in the monoclinic superspace group $X 2 / m(\alpha, 0, \mathrm{~g}) 00$, with modulation vector $q=$ (0.184(2), 0, 0.347(1)), $a=413.99(9), b=963.83(11)$, $c=410.52(16) \mathrm{pm}$, and $b=90.11(1)^{\circ}$ at $120 \mathrm{~K}$. The modulation wave occurs in the $\mathrm{Ga} / \mathrm{Cu}$ disordered sublattice and $q$ was found to be similar at both temperatures. Furthermore, analysis of the reciprocal pattern of $\mathrm{ErCu}_{05} \mathrm{Ga}_{35}$ also indicates a twinning effect, described by a two-fold axis around $a^{*}$.

[1] Yu. Verbovytskyy, A.P. Gonçalves, Chem. Met. Alloys 5 (2012) 129.

[2] Yu. Verbovytskyy, A.P. Gonçalves, Intermetallics 33 (2013) 16.

[3] V.Ya. Markiv, et al., Dopov. Akad. Nauk Ukr. RSR, Ser. A 7 (1985) 76.

[4] Yu. Verbovytskyy, M. Pasturel, T. Roisnel, A.P. Gonçalves, XIV Scientific Conference "Lviv Chemical Readings - 2013", Book of Abstracts, Lviv, Ukraine, 26-29 May 2013, H5.

Keywords: incommensurate, occupation modulation, intermetallics 